Document downloaded from:

http://hdl.handle.net/10251/83608

This paper must be cited as:

Aguilar, V.; Sandoval, C.; Adam Martínez, JM.; Garzón-Roca, J.; Valdebenito, G. (2016). Prediction of the shear strength of reinforced masonry walls using a large experimental database and artificial neural networks. Structure and Infrastructure Engineering. 12(12):1661-1674. doi:10.1080/15732479.2016.1157824.

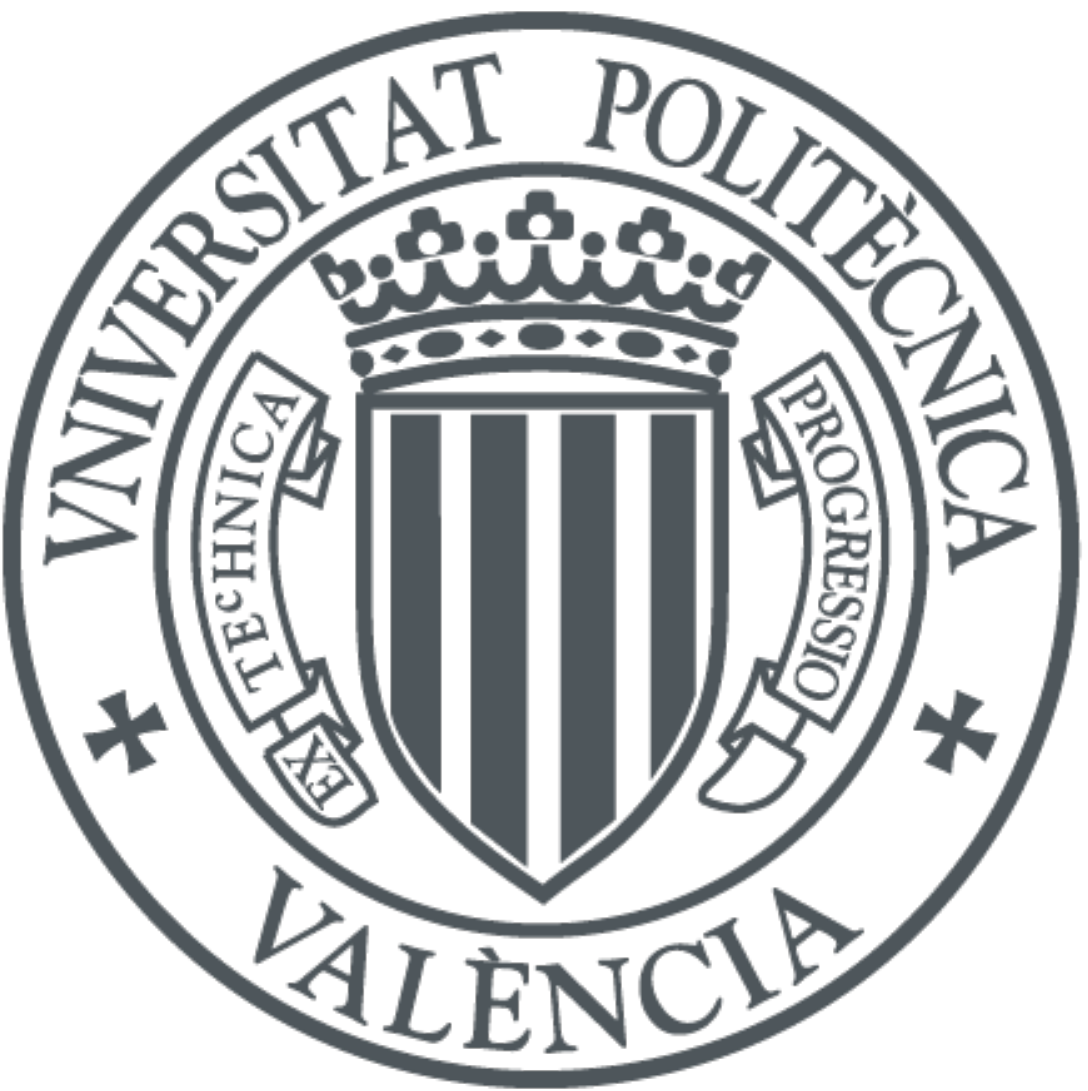

The final publication is available at

http://dx.doi.org/10.1080/15732479.2016.1157824

Copyright Taylor \& Francis (Routledge)

Additional Information 


\title{
Prediction of the shear strength of reinforced masonry walls using a large experimental database and artificial neural networks
}

\author{
Víctor Aguilar $^{\mathrm{a}}$, Cristián Sandoval ${ }^{\mathrm{b}, *}$, Jose M. Adam $^{\mathrm{c}}$, Julio Garzón-Roca ${ }^{\mathrm{d}}$, Galo Valdebenito ${ }^{\mathrm{a}}$
}

${ }^{a}$ Institute of Civil Engineering, Universidad Austral de Chile, General Lagos 2086, Valdivia, Chile

${ }^{\mathrm{b}}$ Department of Structural and Geotechnical Engineering, and School of Architecture, Pontificia Universidad Católica de Chile, Vicuña Mackena 4860, Santiago, Chile

cICITECH, Departamento de Ingeniería de la Construcción y Proyectos de Ingeniería Civil, Universitat Politècnica de València, Camino de Vera s/n, 46071, Valencia, Spain

${ }^{\mathrm{d}}$ Departamento de Ingeniería del Terreno, Universitat Politècnica de València, Camino de Vera s/n, 46071, Valencia, Spain

\begin{abstract}
This paper analyses the accuracy of a selection of expressions currently available to estimate the in-plane shear strength of reinforced masonry (RM) walls, including those presented in some international masonry codes. For this purpose, predictions of such expressions are compared with a set of experimental results reported in the literature. The experimental database includes specimens built with ceramic bricks and concrete blocks tested in partially and fully grouted conditions, which typically present a shear failure mode. Based on the experimental data collected and using artificial neural networks (ANN), this paper presents alternative expressions to the different existing methods to predict the in-plane shear strength of RM walls. The wall aspect ratio, the axial pre-compression level on the wall, the compressive strength of masonry, as well as the amount and spacing of vertical and horizontal reinforcement throughout the wall are taken into consideration as the input parameters for the proposed expressions. The results obtained show that ANN-based proposals give good predictions and in general fit the experimental results better than other calculation methods.
\end{abstract}

Keywords: Reinforced masonry; experimental database; shear strength; neural networks; sensitivity analysis

\footnotetext{
* Corresponding author:

E-mail addresses: csandoval@ing.puc.cl (C.Sandoval) - Corresponding author
} 


\section{Introduction}

Reinforced masonry (RM) is a structural typology widely used in construction of low-rise housing, mainly in seismic regions as well as in medium-rise and high-rise buildings in countries such as Brazil and the US. As is well known, a RM wall can be either fully grouted or partially grouted. Fully grouted means that all hollows in the masonry units are completely grouted, while partially grouted implies that only hollows with vertical steel bars are completely grouted. In both cases, horizontal steel bars are placed in horizontal mortar joints or in bond beams. In addition, RM walls can be constructed using hollow concrete blocks or perforated clay bricks.

In recent years, severe earthquake events have affected a large number of masonry structures all over the world. In particular, severe earthquakes have struck Chile, both in the northern region (Tocopilla, 2007 (Mw7.7); Iquique, 2014 (Mw8.2)) and also in the central southern region (Maule, 2010 (Mw8.8)). An acceptable performance of RM buildings was observed during these events. However, unexpectedly severe damage was sustained by a significant number of RM buildings, which even collapsed in a few cases (Astroza, Moroni, Brzev, \& Tunner, 2012; D’Ayala \& Benzoni, 2012; Valdebenito, Alvarado, Sandoval, \& Aguilar, 2015). Therefore, the recent earthquakes have demonstrated once again the high seismic vulnerability of this type of construction and have indicated the need to review the current RM shear strength formulations in order to improve their predictive ability for design, rehabilitation or retrofit purposes.

To date, among the strategies used for the prediction of the shear strength of RM walls subjected to lateral loading, the use of the data mining models applied to a large amount of experimental data has not been yet explored. Essentially, these models can extract high-level knowledge from raw data (Marques \& Lourenço, 2013). In data mining models, certain functions can be trained to predict the value of a desired output from the multiple variables influencing its response. Among the available techniques, the artificial neural networks (ANN) along with support vector machines (SVM) are the most frequently used. The above techniques have been used in several research areas, including structural engineering problems. For example, the SVM technique has recently been used by Marques and Lourenço (2013) to assess the shear strength of confined masonry walls under lateral loading. Similarly, the ANN technique has been used to predict the compressive strength of masonry prisms (Garzón-Roca, Marco, \& Adam, 2013), to predict the shear strength of reinforced concrete beams (Mansour, Dicleli, Lee, \& Zhang, 2004), or to predict the load-bearing capacity of unreinforced masonry walls, taking buckling failure into account (Garzón-Roca, Adam, Sandoval, \& Roca, 2013; Sandoval, Roca, Adam, \& Garzón-Roca, 2014). Šipoš, Sigmund, and Hadzima-Nyarko (2013) use ANN to predict the effect of various important factors that affect the performance of reinforced-concrete frames with masonry infill subjected to in-plane lateral loads, while Plevris and Asteris (2014) use ANN to model the masonry failure surface under biaxial compressive stress.

In this paper, the accuracy of a set of available expressions to estimate the shear strength of RM walls is analysed by comparison with a large experimental database built on-purpose for this research. The experimental data gathered here include single-story RM walls, tested in cantilever or double fixed 
conditions. Later, and as an alternative to the current calculation methods, this paper presents expressions to predict the shear strength of RM walls using ANN. As already mentioned, the use of ANN in structural engineering problems is not a novelty; however, its application to the case of RM walls is an original aspect. The ANN model presented here was trained and tested using data collected from the literature involving a total of $285 \mathrm{RM}$ walls. The ANN-based expressions include equations for fully grouted concrete masonry walls (CB FG), fully grouted brick masonry walls (BR FG) and partially grouted brick masonry walls (BR PG). The performance of the ANN-based proposals is presented and discussed in comparison with the experimental database and with other shear expressions available in the literature.

\section{Review of the State-of-the-art}

Given the importance of the seismic action, many experimental studies on the in-plane shear behaviour of RM walls have been carried out worldwide. A large proportion of this experimental research has been conducted using fully grouted RM walls (Brunner \& Shing, 1996; El-Dakhakhni, Banting, \& Miller, 2013; Ibrahim \& Sutter, 1999; Kikuchi et al., 2004; Matsumura, 1988; Okamoto, Yamazaki, Kaminosono, Teshigawara, \& Hirashi, 1987; Shedid, Drysdale, \& El-Dakhakhni, 2008;Shing, Noland, Klamerus, \& Spaeh, 1989; Shing, Schuller, \& Hoskere, 1990; Sherman, 2011; Sucuoglu \& McNiven, 1991; Sveinsson et al., 1985; Tomaževič, Lutman, \& Petković, 1996; Voon \& Ingham, 2006), while another considerable number have been conducted on the partially grouted typology (Chen, Hidalgo, Mayes, Clough, \& McNiven, 1978; Dhanasekar \& Haider, 2011; Elmapruk, 2010; Fattal, 1993; Ghanem, Essawy, \& Hamid, 1992; Ghanem, Salama, Elmagd, \& Hamid, 1993; Ingham, Davidson, Brammer, \& Voon, 2001; Maleki, 2008; Minaie, Mota, Moon, \& Hamid, 2010; Nolph \& ElGawady, 2012; Schultz, 1994; Voon \& Ingham, 2006; Yancey \& Scribner, 1989). Other RM systems, traditionally developed in Europe, make use of perforated clay units combined with concentrated vertical reinforcement (da Porto, Mosele, \& Modena, 2011; Haach, Vasconcelos, \& Lourenço, 2010).

In Chile, investigations have been focused mainly on the experimental response of partially grouted RM walls because of their greater abundance in the building stock (Alcaino \& Santa-Maria, 2008; Diez, 1987; Hidalgo \& Lüders, 1982; Lüders \& Hidalgo, 1986; Lüders, Hidalgo, \& Gavilán, 1985; Muñoz, 1992; Ramírez, Sandoval, \& Almazán, 2015; Sandoval, Calderón, Almazán, \& Tapia, in press; Sepúlveda, 2003; Sierra, 2002). In spite of the large amount of experimental works reported in the literature, it should be noted that not all the studies are well documented, making it difficult to organise any experimental database.

The majority of the aforementioned experimental research studies recognise the influence of parameters such as wall aspect ratio (defined as the relation between the height and length of the wall), level of axial compressive stress, masonry compressive strength, and the amount and spacing of vertical and horizontal reinforcement, on the structural response of RM walls. Two main failure mechanisms can be identified in RM walls subjected to in-plane lateral loading that depend on these parameters (Brunner \& Shing, 1996; Shing et al., 1989; Voon \& Ingham, 2006). The first of these is flexural failure, which is generally characterised by tensile yielding of flexural reinforcement and masonry crushing at wall toes. The second 
failure mechanism is the shear failure mode, which is mainly characterised by diagonal tensile cracking. In general, flexural capacity of an RM wall can be accurately predicted by means of analytical models (Shing et al., 1990), while predicting the shear strength can be a difficult task, due to the complexity of the mechanisms involved in the shear failure mode. According to Voon (2007), these mechanisms can include the tension of horizontal reinforcement, the dowel action of vertical reinforcement, as well as an additional frictional strength along diagonal cracking. The complex behaviour of these shear resistance mechanisms, together with their mutual interactions, greatly complicates the development of analytical models. As a result, the majority of available expressions to predict the shear strength of RM walls are semi-empirical equations usually calibrated from experimental test results. Consequently, similar approaches have been adopted by the international RM codes.

The problem of estimating the in-plane shear strength of RM walls has been an important research topic in the past three decades. Different expressions have been proposed to predict the shear strength of both fully grouted and partially grouted RM shear walls (Anderson \& Priestley, 1992; Banting \& El-Dakhakhni, 2014; Fattal, 1993; Matsumura, 1988; Psilla \& Tassios, 2009; Shing et al., 1990; Tomazevic, 1999; Voon \& Ingham, 2007). Among the proposed methods are also the expressions adopted in international masonry codes (US: ACI Committee 530, 2011; Canada: CSA-S304.1-04, 2004; New Zealand: NZS-4230, 2004; Mexico: IMNC, 2010). The description and performance of eight of these expressions are exposed in Section 4.

A large number of existing expressions calculates the maximum shear strength of an RM wall as the sum of the contributions of masonry, horizontal reinforcement, and the effect of the axial compressive load applied. However, the equations used to describe each contribution vary considerably between shear expressions, resulting in different levels of complexity and accuracy. In fact, some researchers (Davis, 2008; Hassanli, ElGawady, \& Mills, 2014; Minaie et al., 2010) have shown that several of these shear expressions can be unconservative in predicting the shear strength of RM walls, including expressions presented in some international masonry codes. Even though numerous studies have shown that partially grouted walls behave differently than fully grouted walls, it is important to note that some of the existing expressions used to predict the shear strength of partially grouted RM walls have been initially derived from fully grouted masonry wall tests (Minaie et al., 2010).

\section{Experimental database}

As presented in Section 2, a significant number of experimental works have been carried out to study the shear response of RM walls around the world. A detailed review of these studies shows that shear strength of a RM wall increases as the aspect ratio decreases (da Porto et al., 2011; Matsumura, 1988; Ramírez et al., 2015; Voon \& Ingham, 2006). An increase in axial load causes a rise in the shear strength of the walls (Haach et al., 2010; Matsumura, 1988; Ramírez et al., 2015; Voon \& Ingham, 2006), and an additional frictional strength along the diagonal cracks, which can imply an increase in hysteretic energy dissipation (Minaie et al., 2010). However, an increase in axial load on the walls tends to reduce the ductility and at the 
same time can cause a more brittle behaviour than in walls without an axial load (Ghanem et al., 1993; Haach et al., 2010; Muñoz, 1992; Voon \& Ingham, 2006).

Concerning the influence of the vertical reinforcement ratio, it is observed that if this ratio increases, shear strength also increases (Elmapruk, 2010; Sierra, 2002). However, the benefit of the vertical reinforcement ratio on the lateral strength is not straightforward, due to the predominance of diagonal cracking for medium to high levels of vertical pre-compression (Haach et al., 2011). On the other hand, a greater vertical reinforcement ratio would not appear to affect the displacement ductility or the stiffness of the walls (Nolph \& ElGawady, 2012). Regarding the horizontal reinforcement ratio, it has been demonstrated that an increase in this ratio leads to a rise in shear strength (Matsumura, 1988; Sepúlveda, 2003; Voon \& Ingham, 2006), to a reduction in the degradation of stiffness and a substantial improvement in the structural integrity of the walls (da Porto et al., 2011; Schultz et al., 1998). However, after a certain ratio, its influence seems not to improve a wall's shear strength (Elmapruk, 2010; Haach et al., 2011; Shing et al., 1989). Moreover, according to Sepúlveda (2003) and Haach et al. (2011), the contribution of the horizontal reinforcement to the shear strength of the RM walls only begins once the diagonal cracking has occurred.

Many of the aforementioned experimental studies, which cover a wide range of design parameters, have been collected in previous studies. Voon (2007) gathered 56 fully grouted concrete and clay brick masonry wall tests and then compared nine existing expressions for predicting the shear strength. Davis (2008), using the database published by Voon (2007), investigated the effectiveness of eight different code provisions and proposed design expressions. Minaie et al. (2010) gathered the experimental results of 60 partially grouted masonry walls and then compared seven empirically derived shear strength expressions. More recently, Hassanli et al. (2014) examined the performance of four international design codes using the experimental results of 89 partially grouted masonry walls constructed with concrete masonry units. In this context, this research complements and expands the experimental database that other authors have already reported with more recent experimental results. It should be noted that not all studies reported in the literature are well documented, so the authors had to use a certain amount of engineering judgement in order to assume some parameters that were not reported.

The database constructed here gathers 285 experimental results of RM walls built in four different typologies. It contains data of 96 fully grouted concrete block walls (CB-FG), 95 partially grouted concrete block walls (CB-PG), 37 fully grouted ceramic brick walls (BR-FG) and 57 partially grouted ceramic brick walls (BR-PG). According to the typology, Table 1 summarises the experimental database, as well as the number of samples considered in this research. All the selected walls were subjected to either monotonic or cyclic lateral displacement until failure occurred. It is important to note that the experimental results used were from specimens that have shown a shear failure mode. 
Table 1 - Experimental database. References, typology and samples list.

\begin{tabular}{lcclcc}
\hline Reference & \multicolumn{2}{l}{ Typology \# of samples } & Reference & \multicolumn{2}{c}{ Typology \# of samples } \\
\hline Haach et al. (2010) & CB FG & 6 & Lüders \& Hidalgo (1982) & BR FG & 6 \\
Kikuchi et al. (2004) & CB FG & 9 & Matsumura (1988) & BR FG & 4 \\
Lüders \& Hidalgo (1986) & CB FG & 10 & Shing et al. (1990) & BR FG & 2 \\
Matsumura (1988) & CB FG & 14 & Sucuoglu \& McNiven (1991) & BR FG & 10 \\
Okamoto et al. (1987) & CB FG & 8 & Sveinsson et al. (1985) & BR FG & 15 \\
Shing et al. (1990) & CB FG & 8 & Alcaino \& Santa María (2008) & BR PG & 3 \\
Sucuoglu \& McNiven & CB FG & 8 & Chen et al. (1978) & BR PG & 7 \\
Sveinsson et al. (1985) & CB FG & 10 & Dhanasekar \& Haider (2011) & BR PG & 9 \\
Tomazevic et al. (1996) & CB FG & 16 & Diez (1987) & BR PG & 6 \\
Voon \& Ingham (2006) & CB FG & 7 & Lüders \& Hidalgo (1982) & BR PG & 2 \\
Chen et al. (1978) & CB PG & 4 & DICTUC (2014) & BR PG & 2 \\
Ramirez et al. (2015) & CB PG & 9 & Matsumura (1988) & BR PG & 2 \\
Elmapruk (2010) & CB PG & 6 & Sandoval et al. (2016) & BR PG & 10 \\
Lüders \& Hidalgo (1986) & CB PG & 11 & Sepulveda (2003) & BR PG & 12 \\
Matsumura (1988) & CB PG & 29 & Sierra (2002) & BR PG & 4 \\
Minaie et al. (2010) & CB PG & 4 & & & \\
Muñoz (1992) & CB PG & 5 & & & \\
Nolph \& ElGawady & CB PG & 5 & & & \\
Schultz (1994) & CB PG & 6 & & & \\
Sierra (2002) & CB PG & 4 & & & \\
Voon \& Ingham (2006) & CB PG & 2 & & & \\
Yancey \& Scribner & CB PG & 10 & & & \\
\hline
\end{tabular}

The database was constructed and assembled with the parameters required to assess the existing shear expressions. Basic geometrical properties such as aspect ratio, wall thickness and the net area are required. Similarly, parameters such as compressive strength of masonry, axial compressive load on the section under consideration, ratio of the horizontal and vertical reinforcing steel and yield strength of the reinforcement are also needed. However, only the maximum value of the shear strength of each specimen is considered as output parameter. The range of input parameters included in the database is shown in Table 2 and their distribution is drawn in Figure 1. As observed, the tested walls had an aspect ratio ranging from .36 to 2.28, although a large part of them had an aspect ratio close to 1.0. In fact, almost all walls of the BR-FG typology present this aspect ratio. The inventory of existing experimental data shows that average values of compressive strength of masonry composite are 16.8 MPa (CB-FG), 10.9 MPa (CB-PG), 19.5 MPa (BR-FG) and 14.2 MPa (BR-PG). As regards the level of axial load applied, it can be observed that most walls have been tested under null axial load or considering an axial load level equal to $10 \%$ of the masonry compressive strength. The horizontal reinforcement ratios considered in the existing experimental works, which are summarised in Figure 1(c), indicate that a large number of walls were tested using ratios equal to or less than $4 \%$. A comprehensive description of the experimental database generated on-purpose for this research can be found in Aguilar (2013). 
Table 2 - Range of input parameters in the database

\begin{tabular}{|ll|c|c|c|c|c|}
\cline { 3 - 7 } \multicolumn{2}{l|}{} & \multicolumn{4}{c|}{ Typology } \\
\hline Property & & Unit & CB FG & CB PG & BR FG & BR PG \\
\hline $\begin{array}{l}\text { Compressive strength of } \\
\text { masonry }\end{array}$ & $\left(f_{m}^{\prime}\right)$ & $\mathrm{N} / \mathrm{mm}^{2}$ & $5.2-34.6$ & $4.3-18.5$ & $6.7-28.6$ & $3.9-31.1$ \\
$\begin{array}{l}\text { Normal stress/compressive } \\
\text { strength ratio }\end{array}$ & $\left(\sigma / f_{m}^{\prime}\right)$ & - & $0-0.38$ & $0-0.14$ & $0-0.14$ & $0-0.09$ \\
$\begin{array}{l}\text { Vertical } \\
\text { reinforcement ratio }\end{array}$ & $\left(\rho_{v}\right)$ & - & $0.001-0.0115$ & $0-0.0145$ & $0.0013-0.0067$ & $0-0.011$ \\
$\begin{array}{l}\text { Horizontal reinforcement } \\
\text { ratio }\end{array}$ & $\left(\rho_{h}\right)$ & - & $0-0.0067$ & $0-0.0034$ & $0-0.0067$ & $0-0.0021$ \\
Wall aspect ratio & $(H / L)$ & - & $0.36-2.28$ & $0.36-1.96$ & $1-1.53$ & $0.53-2.02$ \\
\hline
\end{tabular}

a) Wall aspect ratio

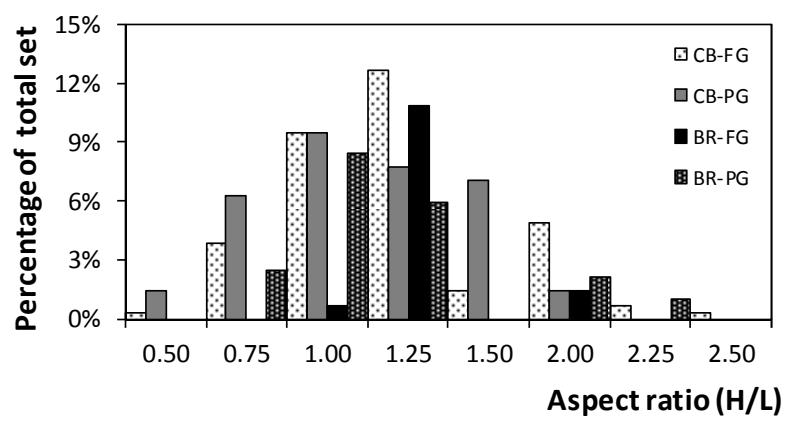

c) Normal stress/compressive strength ratio

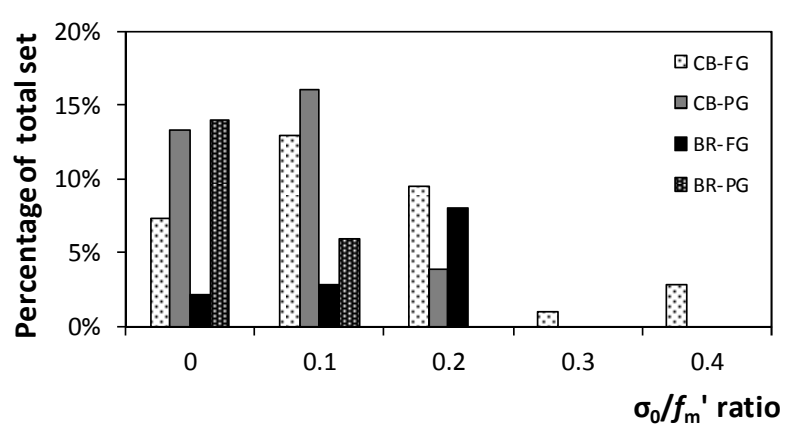

b) Masonry compressive strength

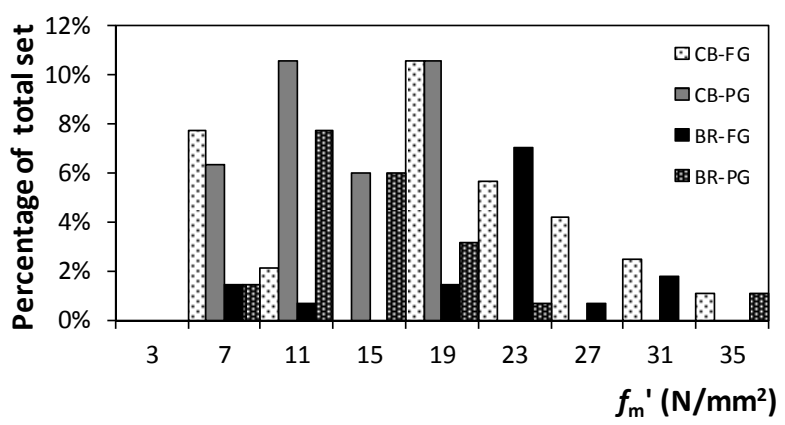

d) Horizontal reinforcement ratio

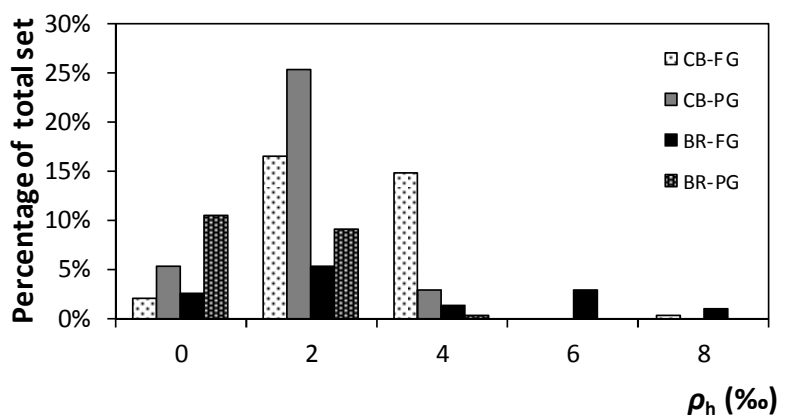

Figure 1 - Distribution of the main input parameters of the experimental database

\section{Performance of existing expressions for the shear strength of RM walls}

As a product of the research conducted so far, there are different existing expressions to estimate the maximum shear strength of RM walls. This section presents eight of these expressions and their ability to predict the shear strength in experimental tests is evaluated by means of a statistical comparison. 


\subsection{Existing shear expressions}

The expressions selected to predict the shear strength of an RM wall include parameters such as the compressive strength of masonry, the ratio and yield strength of horizontal and vertical reinforcing steel, the aspect ratio, the axial load level and the cross-sectional area. Each expression is presented with a similar notation. It should be noted that the expressions here analysed were selected in order to compare their results with the findings of previous studies. Some existing expressions were not selected due to lack of accurate information for their proper application.

Most authors suggest that the shear capacity of an RM wall improves by increasing the square root of the masonry compressive strength. Similarly, all expressions recognise the influence of horizontal reinforcing steel. In addition, virtually all expressions recognise that the aspect ratio, either as $(\mathrm{H} / \mathrm{L})$ or $(\mathrm{M} / \mathrm{Vd})$, has an effect such that if this ratio increases, the shear strength decreases. The participation of the pre-compression level in the shear strength is also widely recognised in the studied formulations, either as the axial load term $\mathrm{P}$ or axial stress term $\sigma$. The existing expressions for predicting the shear strength were considered as follows.

\subsubsection{ACI-530 (2005)}

The American code, also known as the MSJC (2011), states that the shear strength of the wall may be estimated as the addition of three contributions: masonry, axial compression, and horizontal reinforcement. The shear expression is given by:

$V_{n}=0.083\left[4-1.75\left(\frac{M}{V d_{v}}\right)\right] A_{n} \sqrt{f_{m}^{\prime}}+0.25 P+0.5 \frac{A_{s h}}{s_{h}} f_{y h} d_{v}$

where $\mathrm{M}$ and $\mathrm{V}$ are the maximum moment and shear force at the section under consideration, while $\mathrm{d}_{\mathrm{v}}$ is the depth of the section of wall. $A_{n}$ is the net cross-sectional area, $\mathrm{f}_{\mathrm{m}}^{\prime}$ is the compressive strength of masonry, $\mathrm{P}$ is the axial load at the section, $A_{s h}$ is the horizontal steel area, $s_{h}$ is the spacing among horizontal reinforcement steel bars and $\mathrm{f}_{\mathrm{yh}}$ is the yield strength of the horizontal reinforcement.

\subsubsection{CSA-S304 (2004)}

The Canadian masonry design standard recognizes the contribution of the masonry shear strength, the axial compression load, and the horizontal reinforcement contribution.

$$
V_{n}=\rho_{m}\left(v_{m} b_{w} d_{v}+0.25 P\right) \gamma_{g}+\rho_{s}\left(0.6 A_{s h} f_{y h} \frac{d_{v}}{s_{h}}\right) \leq 0.4 \rho_{m} \sqrt{f_{m}^{\prime}} b_{w} d_{v} \gamma_{g}
$$

In this equation, $\mathrm{v}_{\mathrm{m}}$ is the contribution of masonry shear strength, which is determined by the expression $\mathrm{v}_{\mathrm{m}}=0.16\left(2-\frac{\mathrm{M}}{\mathrm{VL}}\right) \sqrt{\mathrm{f}_{\mathrm{m}}^{\prime}}$, where $\mathrm{f}_{\mathrm{m}}^{\prime}$ is the compressive strength of masonry, $\mathrm{M}$ and $\mathrm{V}$ are the maximum moment and shear force of the section under consideration and $\mathrm{L}$ is the length of the wall. In the equation (2), 
$b_{w}$ is the wall width and $P$ is the axial compressive load on the section under consideration, $A_{s h}$ is the crosssectional area of horizontal shear reinforcement, $f_{y h}$ is the yield strength of horizontal reinforcement, $d_{v}$ is the effective depth of the section of wall and $s_{h}$ the vertical spacing of shear reinforcement. The equation also includes the factor $\gamma_{\mathrm{g}}$ that takes into account the filling condition of a RM wall. For fully grouted walls, $\gamma_{\mathrm{g}}$ is equal to 1.0. For partially grouted walls, $\gamma_{\mathrm{g}}$ takes the value of the ratio $\mathrm{A}_{\mathrm{e}} / \mathrm{A}_{\mathrm{g}}$ not greater than 0.5, where $A_{e}$ and $A_{g}$ are the effective and gross cross-sectional area of masonry. Meanwhile, $\rho_{m}$ and $\rho_{s}$ are resistance reduction factors of masonry and steel reinforcement respectively.

\subsection{3 $\operatorname{IMNC}(2010)$}

In the Mexican masonry code, the shear strength is given by

$V_{n}=F_{R}\left(0.5 v_{m} A_{T}+0.3 P\right)+F_{R} \eta \rho_{h} f_{y h} A_{T} \quad$ with $\eta=\left\{\begin{array}{l}0.6 \text { if } \rho_{h} f_{y h} \leq 0.6 \\ 0.2 \text { if } \rho_{h} f_{y h} \geq 0.9\end{array}\right.$

but no greater than $V_{n}=1.5 F_{R} V_{m} A_{T}$, where the contribution of masonry shear strength $v_{m}$ can be determined by the expression $v_{\mathrm{m}}=0.25 \sqrt{\mathrm{f}_{\mathrm{m}}^{\prime}}$. The term $\mathrm{f}_{\mathrm{m}}^{\prime}$ is the compressive strength of masonry, $\mathrm{A}_{\mathrm{T}}$ is the gross cross-sectional area of the wall, $\mathrm{P}$ is the axial compressive load on the section under consideration and $\eta$ is an efficiency factor of the horizontal reinforcement, which depends of the horizontal reinforcement ratio $\left(\rho_{h}\right)$ and the yield strength of horizontal reinforcement $\left(f_{y h}\right)$.

\subsubsection{UBC (1997)}

According to this proposal, the shear strength is obtained by adding two terms: the contribution provided by the masonry and the contribution provided by the horizontal shear reinforcement. This shear expression do not considers the contribution of the axial compressive load.

$V_{n}=0.083 C_{d} A_{n} \sqrt{f_{m}^{\prime}}+A_{s h} f_{y h} \frac{L_{w}}{S_{h}} \quad \begin{aligned} & \text { with } C_{d}=2.4+1.6\left\langle\alpha r_{d}-1\right\rangle-1.6\left\langle\alpha r_{d}-0.25\right\rangle \\ & \text { and } \alpha=\frac{M}{V L r}\end{aligned}$

where $A_{n}$ is the net cross-sectional area of the wall, $\mathrm{f}_{m}^{\prime}$ is the compressive strength of masonry, $A_{s h}$ is the horizontal steel area, $f_{y h}$ is the yield strength of horizontal reinforcing steel, $L_{w}$ is the wall length and $s_{h}$ is the spacing among horizontal reinforcement steel bars. In the term $\alpha, r$ is the ratio between wall height and wall length, while $r_{d}$ is the ratio between wall height and wall effective length.

\subsubsection{Shing et al. (1990)}

This shear expression follows the traditional form in that there is a contribution of masonry, of compression axial load, and of shear reinforcement. In contrast to the previous expressions, this equation recognizes a certain contribution of the vertical reinforcement on the shear strength. 
$V_{n}=\left(0.166+0.0217 \rho_{v} f_{y v}\right) A_{n} \sqrt{f_{m}^{\prime}}+0.0217 \sigma A_{n} \sqrt{f_{m}^{\prime}}+\left(\frac{L_{w}-2 d^{\prime}}{s_{h}}\right) A_{s h} f_{y h}$

In this equation $\rho_{\mathrm{v}}$ is the vertical reinforcement ratio, $\mathrm{f}_{\mathrm{yv}}$ is the yield strength of vertical reinforcing steel, $A_{\mathrm{n}}$ is the net cross-sectional area of the wall, $\mathrm{f}_{\mathrm{m}}^{\prime}$ is the compressive strength of masonry, $\sigma$ is the acting vertical normal stress on the wall, $\mathrm{L}_{\mathrm{w}}$ is the wall length, $\mathrm{s}_{\mathrm{h}}$ is the spacing among horizontal reinforcement steel bars, $\mathrm{d}^{\prime}$ is the cover of reinforcement of the vertical edge, $A_{\mathrm{sh}}$ the cross-sectional area of the horizontal shear reinforcement and $f_{y h}$ is the yield strength of reinforcement.

\subsubsection{Matsumura (1988)}

This equation also includes a masonry term, along with compression axial load and shear reinforcement terms. According to this proposal, the masonry contribution to the shear strength is affected by the aspect ratio and the edge vertical reinforcement. In addition, it establishes a relation between the horizontal reinforcement and the compressive strength of the masonry.

$V_{n}=\left[k_{u} k_{p}\left(\frac{0.76}{\frac{h}{d}+0.7}+0.012\right) \sqrt{f_{m}^{\prime}}+0.2 \sigma+0.18 \gamma \delta \sqrt{\rho_{s h} f_{y h} f_{m}^{\prime}}\right](0.875 t d)$

where $\mathrm{k}_{\mathrm{u}}=1.0$ for fully grouted walls, $\mathrm{k}_{\mathrm{u}}=0.8$ for partially grouted brick masonry walls, $\mathrm{k}_{\mathrm{u}}=0.64$ for partially grouted concrete masonry walls; $\mathrm{k}_{\mathrm{p}}=1.16\left(\rho_{\mathrm{ve}}\right)^{0.3}$; meanwhile, the term $\gamma$ can be either 1.0 for fully grouted walls or 0.6 for partially grouted walls, and $\delta=1.0$ for loading resulting in inflection point at mid-height of walls (double bending) or $\delta=0.6$ for loading of cantilever type (single bending). In addition, the terms $h$ and $d$ are the height and the effective depth of the wall, respectively. $f_{m}^{\prime}$ is the compressive strength of masonry, $\sigma$ is the acting vertical normal stress on the wall, $\rho_{\mathrm{sh}}$ is the horizontal reinforcement ratio, $f_{y h}$ is the yield strength of the horizontal reinforcement, $t$ is the wall thickness and $\rho_{v e}$ is the vertical reinforcement ratio of one edge of the wall.

\subsubsection{Tomazevic (1999)}

This formulation recognizes the contribution of masonry as well as the contribution of horizontal reinforcement and it also proposes a term to consider the dowel effect of the vertical reinforcement, which depends on the resistance of the filling grout. The Tomazevic's expression is given by:

$V_{n}=A_{n}\left(\frac{f_{t}}{b}\right)\left(\sqrt{\frac{\sigma}{f_{t}}+1}\right)+\Phi A_{s h} f_{y h}+1.026 A_{s v} \sqrt{f_{j} f_{y v}}$

where $A_{n}$ is the net cross-sectional area of the wall, $b$ is the shear stress distribution factor, $\sigma$ is the acting vertical normal stress on the wall, $\mathrm{f}_{\mathrm{t}}$ is the tensile strength of the masonry (in this research, a $4 \%$ of the compressive strength was used when this parameter is not reported (Sandoval \& Roca, 2012)), $A_{\text {sh }}$ is the 
cross-sectional area of horizontal shear reinforcement, $\mathrm{f}_{\mathrm{yh}}$ is the yield strength of shear reinforcement, $\Phi$ is a reduction factor of the shear reinforcement, $A_{s v}$ is the cross-sectional area of vertical reinforcement, $f_{y v}$ is the yield strength of the vertical reinforcement and $f_{j}$ is the compressive strength of the filling grout.

\subsubsection{Anderson \& Priestley (1992)}

According to this proposal, the shear strength is obtained by adding the contribution from three components: masonry, compression axial load and horizontal reinforcement.

$V_{n}=C_{a p} A_{n} k \sqrt{f_{m}^{\prime}}+0.25 \sigma A_{n}+0.5 A_{s h} f_{y h} \frac{d}{s_{h}}$

In this expression, $\mathrm{C}_{\mathrm{ap}}$ is a coefficient that takes into account the type of masonry used in construction, and it is specified as 0.24 and 0.12 for concrete and clay brick masonry, respectively. $A_{n}$ is the net cross-sectional area of the wall, $\mathrm{f}_{\mathrm{m}}^{\prime}$ is the compressive strength of masonry, $\sigma$ is the acting vertical normal stress on the wall, $A_{s h}$ is the cross-sectional area of horizontal reinforcement, $f_{y h}$ is the yield strength of horizontal reinforcement, $\mathrm{d}$ is the effective depth of the section of wall and $\mathrm{s}_{\mathrm{h}}$ is the spacing among horizontal reinforcement steel bars. In addition, this expression takes into account the degradation of shear strength when the wall is subjected to cyclic loading into the inelastic range through the ductility coefficient factor $\mathrm{k}$. The authors suggest that the $\mathrm{k}$ factor be equal to 1.0 for a flexural ductility ratio up to 2.0 , while it should linearly decreases from 1.0 to zero as the ductility ratio increases from 2.0 to 4.0 . In this study, the ductility ratio of walls was taken as 2.0 when this information is not reported.

As it is mentioned previously, some researchers have evaluated the predictive ability of these and other expressions of shear strength available in the literature. Fattal \& Todd (1991) compared the predictive ability of the expressions proposed by Shing et al. (1990), Matsumura (1988), Okamoto et al. (1987) and UBC (in their version of 1988) with a set of 62 experimental data on fully grouted masonry walls. Both clay and concrete unit masonry walls were considered. The authors concluded that the expression given by Matsumura (1988) was the most accurate. In terms of standard deviation, this expression showed the lowest value (0.39 MPa) of the four studied expressions. Psilla\&Tassios (2009) studied the ability of four design equations comparing the prediction of these with 55 experimental data results, concluding that the most accurate code is the NZS 4230. Davis (2008) evaluated several shear strength expressions and the results were compared with an experimental database that included only fully grouted RM walls. The comparison was done in terms of the ratio of test strength to the predicted strength. From the statistical evaluation, the expressions from ACI Committee 530 (2005) and Shing et al. (1990) showed the mean values closest to 1.0 as well as the smallest standard deviation values (0.17 and 0.24 respectively). Meanwhile, Hassanli et al. (2014) evaluated the predictions of four international codes considering only experimental results of partially grouted RM walls. The statistical results show a high scatter of the predicted values for all studied expressions. Again, ACI Committee 530's expression (2005) showed the lowest standard deviation value 
$(0.25)$ and mean value closest to $1.0(0.86)$. The latter authors also conclude that it is necessary to review the provisions of several design codes.

\subsection{Accuracy of existing shear expressions}

The above shear expressions were analysed to test their accuracy in predicting shear resistance. For this, the predictions of each shear expression were correlated with the collected experimental results described in Section 2, following the methodology used by Voon (2007). In this manner, the comparison is done in terms of the $V_{\text {exp }} / V_{n}$ ratio, where $V_{\text {exp }}$ is the experimentally obtained shear strength and $V_{n}$ is the predicted shear strength. The comparative analysis is conducted by means of statistic parameters such as mean, standard deviation and 5th percentile. For the $V_{\text {exp }} / V_{n}$ ratio, a mean value close to one means that the prediction is satisfactory. A $V_{\text {exp }} / V_{n}$ ratio larger than one means that the shear capacity has been underestimated and that the prediction is conservative. If the $V_{\text {exp }} / V_{n}$ ratio is less than one, the shear strength prediction has been overestimated and the prediction is nonconservative. In addition, in the statistical analysis, the 5th percentile value indicates the ratio whereby $95 \%$ of walls failed at loads equal to or higher than predicted by shear expressions.

Table 3 shows the results of the statistical analysis of each RM typology. It can be observed that partially grouted masonry specimens present the highest values of standard deviation for the experimental/predicted shear strength ratios, especially in the case of RM walls constructed with concrete blocks. This could be due to the less homogeneous composition of the walls with partially filled cells.

Dismissing those expressions that show standard deviations greater than .40 , a statistical comparison shows that the most accurate equations in terms of average $V_{\text {exp }} / V_{n}$ ratio are the expressions proposed by Tomazevic (1999) in the case of fully grouted concrete blocks and by Matsumura (1988) in the case of fully grouted ceramic bricks. In typologies with partial grouting, the expression from ACI Committee (2005) shows the more accurate predictions. On the other hand, the 5th percentile values show more accurate results were provided by CSA-S304 (2004) for CB FG, IMNC (2010) for BR FG and Shing et al. (1990) for BR PG. In addition, for CB PG's typology, the 5th percentile results obtained in all equations analysed are low, indicating that a large number of predictions are nonconservative estimations.

Table 3 also illustrates that the proposal of ACI Committee (2005) provides good predictions with low standard deviations in all RM typologies. However, 5th percentile values imply that a significant number of predictions are nonconservative. This is consistent with the results reported by Davis (2008) and Hassanli et al. (2014). Likewise, the proposal of Matsumura (1988) gives very good results on FG masonry typology, consistent with the work by Fattal and Todd (1991). It is also worth noting that, despite its simplicity, the expression from IMNC (2010) gives conservative predictions with small deviations for BR FG typology.

On the other hand, the expression proposed by Anderson and Priestley (1992) is considered excessively conservative to predict shear capacity and shows high SD values. The expression from UBC (1997) does not 
include the contribution of the axial load in the calculation of shear strength; this could explain the wide dispersion of the results. Therefore, it is clear that none of the shear expressions analysed here provide a consistently safe prediction of the shear strength of RM walls.

Table 3 - Statistical comparison of existing shear expressions

\begin{tabular}{|c|c|c|c|c|c|c|c|c|c|c|c|c|}
\hline \multirow{3}{*}{ Type } & \multicolumn{3}{|c|}{ ACI 530 (2005) } & \multicolumn{3}{|c|}{ CSA S.304-1 (2004) } & \multicolumn{3}{|c|}{ UBC (1997) } & \multicolumn{3}{|c|}{ IMNC (2010) } \\
\hline & & Standard. & 5 th & & Standard & 5 th & & Standard & 5 th & & Standard & 5 th \\
\hline & Mean & Deviation & percentile & Mean & Deviation & percentile & Mean & Deviation & percentile & Mean & Deviation & percentile \\
\hline CB FG & 1.21 & 0.29 & 0.75 & 1.41 & 0.34 & 0.90 & 0.76 & 0.39 & 0.13 & 1.50 & 0.43 & 0.93 \\
\hline CB PG & 0.98 & 0.38 & 0.52 & 1.09 & 0.40 & 0.52 & 0.58 & 0.29 & 0.25 & 1.06 & 0.50 & 0.47 \\
\hline BR FG & 1.06 & 0.24 & 0.53 & 1.33 & 0.27 & 0.78 & 0.82 & 0.29 & 0.49 & 1.29 & 0.18 & 0.95 \\
\hline BR PG & 1.23 & 0.36 & 0.69 & 1.12 & 0.43 & 0.60 & 1.15 & 0.66 & 0.44 & 1.57 & 0.19 & 0.55 \\
\hline
\end{tabular}

\begin{tabular}{|c|c|c|c|c|c|c|c|c|c|c|c|c|}
\hline \multirow[b]{2}{*}{ Type } & \multicolumn{3}{|c|}{ Shing et al. (1990) } & \multicolumn{3}{|c|}{ Matsumura (1987) } & \multicolumn{3}{|c|}{ Tomazevic (1999) } & \multicolumn{3}{|c|}{ AP (1992) } \\
\hline & Mean & $\begin{array}{c}\text { Sandard } \\
\text { Deviation }\end{array}$ & $\begin{array}{c}5 \text { th } \\
\text { percentile }\end{array}$ & Mean & $\begin{array}{l}\text { Standard. } \\
\text { Deviation }\end{array}$ & $\begin{array}{c}5 \text { th } \\
\text { percentile }\end{array}$ & Mean & $\begin{array}{c}\text { Standard } \\
\text { Deviation }\end{array}$ & $\begin{array}{c}5 \text { th } \\
\text { percentile }\end{array}$ & Mean & $\begin{array}{c}\text { Standard. } \\
\text { Deviation }\end{array}$ & $\begin{array}{c}5 \text { th } \\
\text { percentile }\end{array}$ \\
\hline CB FG & 1.20 & 0.31 & 0.82 & 1.10 & 0.21 & 0.77 & 0.93 & 0.28 & 0.55 & 1.54 & 1.48 & 0.58 \\
\hline CB PG & 1.32 & 0.44 & 0.75 & 1.32 & 0.88 & 0.57 & 0.71 & 0.29 & 0.33 & 1.65 & 1.56 & 0.61 \\
\hline BR FG & 1.04 & 0.38 & 0.53 & 0.97 & 0.21 & 0.67 & 0.90 & 0.18 & 0.61 & 1.71 & 0.91 & 0.95 \\
\hline BR PG & 1.32 & 0.34 & 0.85 & 2.69 & 3.30 & 0.58 & 0.61 & 0.22 & 0.33 & 2.45 & 2.02 & 0.97 \\
\hline
\end{tabular}

\section{Processing with Neural Networks}

\subsection{General description}

An ANN is a computational scheme inspired by the shape of information processing of biological neural networks in humans. The neuron is the basic unit in this operating system. Each neuron receives a set of inputs, processes them and returns an output value (Figure 2). Inside a neuron, inputs are linearly combined according to a set of previously defined weights (adding also a free end, known as bias) and thereafter a transfer function is applied to the result of the combination, giving the output of the neuron. Any kind of function may be used as transfer functions, although linear or sigmoidal functions are the most commonly used.

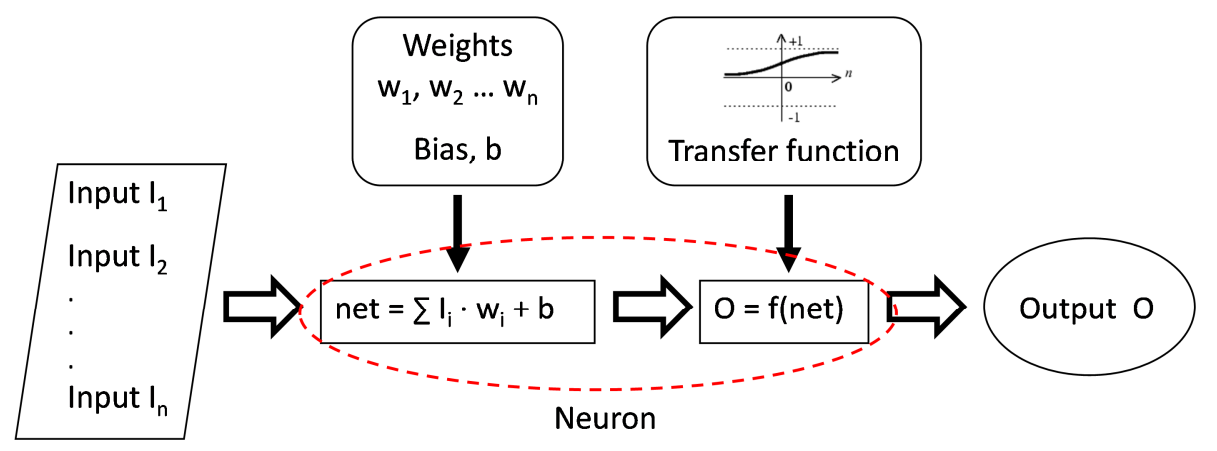

Figure 2 - Single neuron work. 
An ANN is created when a set of neurons acts jointly. The most common ANNs are of multilayer type with onward connections (from inputs to outputs). In these networks, the neurons are arranged in three groups or layers: an input layer that contains the inputs, an intermediate layer known as hidden layer (which may itself contain one or more layers) and an output layer, which generates the output of the network (Figure 3).The number of neurons in each layer will vary depending on the problem under consideration.

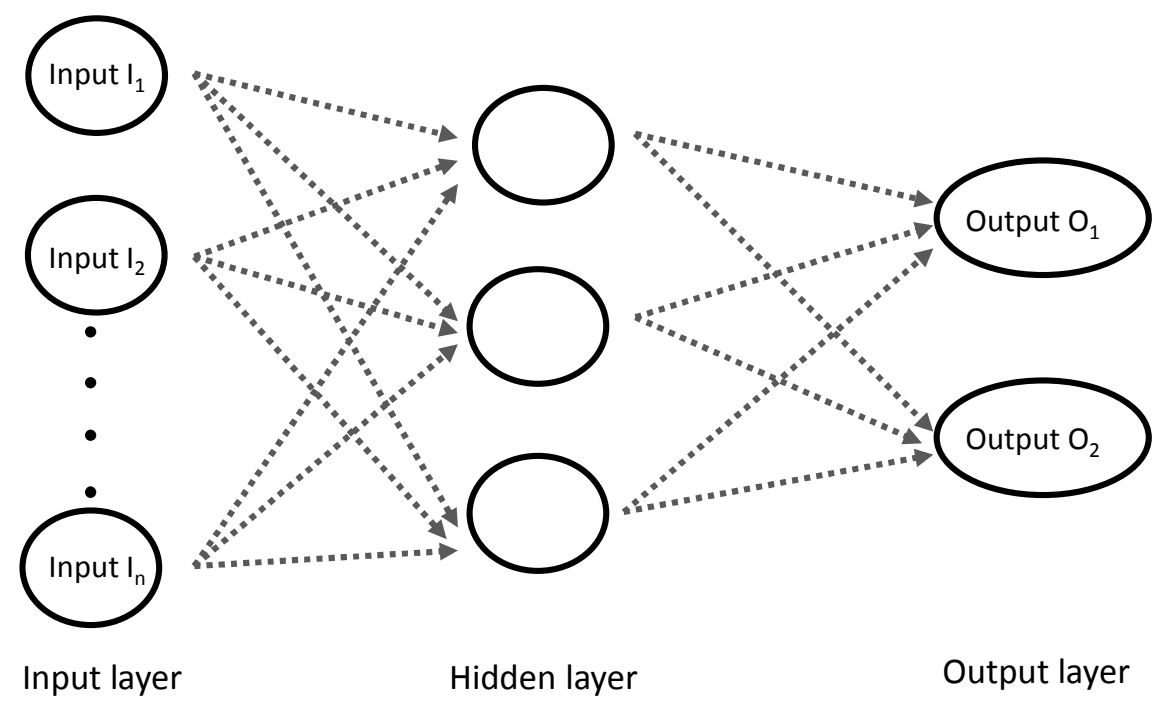

Figure 3 - Feedforward Neural Network

An ANN has the ability to learn from experience, so that it is possible to train the network to recognise certain patterns so as to optimise its performance. As previously explained, in each neuron a linear combination is defined, these coefficients being unknown values in the initial set-up. A learning process may be conducted with known values of inputs and their corresponding outputs. This leads to adjusting the weights and biases of each neuron to minimise the ratio between the target output (real output) and the computed output (output given by the network).

The back-propagation algorithm is one of the most frequently used methods for training a multilayer network with onward connections. In this method, random values are used to set initial weights and biases. The ANN is then processed for the entire set of input data and known outputs, measuring the error or difference between the target output and the computed output. This error is then propagated backwards in order to modify and update the weights and biases, again processing the network with the new values and obtaining a new error. This process is repeated until reaching a minimum error (or until a maximum number of iterations, or epochs, is reached). At this point, the weights and biases are fixed and the ANN can be used to make predictions.

\subsection{Network architecture}

The aim of the ANN constructed was the prediction of the shear strength from geometric and mechanical parameters of RM walls. The ANN was constructed based on the terms used in the expressions with better 
performance according to statistical analyses performed in Section 4 (i.e. proposals of Matsumura, 1988; Tomazevic, 1999; and ACI Committee 530, 2005). Thus, five parameters were defined as inputs: $\sqrt{\mathrm{f}_{\mathrm{m}}^{\prime}} *$ $(\mathrm{M} / \mathrm{VL})^{-1} ; \rho_{\mathrm{h}} \mathrm{f}_{\mathrm{yh}} ; \rho_{\mathrm{v}} \sqrt{\mathrm{f}_{\mathrm{j}} \mathrm{f}_{\mathrm{yv}}} ; \gamma \delta \sqrt{\rho_{\mathrm{h}} \mathrm{f}_{\mathrm{yh}} \mathrm{f}_{\mathrm{m}}^{\prime}} ;$ and $\sigma$. The output layer contained only one neuron, $v_{n}$, predicted shear strength $\left(V_{n}\right)$ divided by the wall cross section $\left(A_{T}\right)$. The Matlab commercial software (MathWorks, Inc., 2005) was used to define a 5-n-1 feedforward network, with a unique hidden layer. The number of neurons in that layer, $n$, was determined by trial and error (there is no generally accepted rule to define the number of neurons the hidden layer should contain, so this trial an error procedure is commonly used).

It is interesting to note that, according to this network architecture, weights may be structured as matrixes, with a matrix called $I W$ with the input weights, i.e. the weights connecting the input values with the neurons in the hidden layer, and a matrix $L W$ with the weights connecting neurons in the hidden layer with the neuron in the output layer. Similarly, biases can be structured in two vectors, $b 1$ and $b 2$, the former associated with matrix $I W$ and the latter associated with matrix $L W$.

The transfer function chosen for the hidden layer was the sigmoid function $g(x)=1 /(1+e-x)$, while the output layer contained a linear neuron. The Lavenberg-Marquardt algorithm (MathWorks, Inc., 2005) with back-propagation was used to train the network using the data previously collected. Since four types of walls are identified in this paper, four ANN where build, one for each type of wall, CB FG, CB PG, BR FG and BR PG. From the total data of each case, an $80 \%$ of it was used to train (calibrate) the network and the rest ( $20 \%$ of data) to validate (test) its performance. Data was randomly picked for a more realistic result. Meansquared error (MSE), defined as shown in Equation (9), measured the error between the target output $\left(T_{i}\right)$ and computed output $\left(O_{i}\right)$. The maximum number of epochs was set to 3000 and the goal for the error was chosen as $10^{-5}$ :

$M S E=\frac{1}{m} \sum_{i=1}^{m}\left(T_{i}-O_{i}\right)^{2}$

With the aim of improving the stability and speed of the training process, both inputs and outputs were scaled by a simple linear normalisation function, given by:

$X_{i, A N N}=\frac{X_{i}}{X_{\max }}$

where for each ANN constructed, $X_{i, A N N}$ represents the normalised value of the input or output and $X_{\max }$ designates the upper bound of the variable $X_{i}$. Maximum and minimum values (range) of the input and output parameters are shown in Table 4. 
Table 4 - Range of input and output parameters in the ANN developed.

\begin{tabular}{|l|l|c|c|c|c|}
\cline { 3 - 6 } \multicolumn{2}{l|}{ Parameter } & \multicolumn{4}{c|}{ Range } \\
\hline P1 & $\sqrt{f_{m}^{\prime}} *(M / V L)^{-1}$ & CB FG & CB PG & BR FG & BR PG \\
P2 & $\rho_{h} f_{y h}$ & $13.973-1.830$ & $14.479-2.195$ & $9.010-2.292$ & $7.624-1.374$ \\
P3 & $\rho_{v} \sqrt{f_{j} f_{y v}}$ & $2.572-0.000$ & $1.292-0.000$ & $2.848-0.000$ & $0.720-0.000$ \\
P4 & $\gamma \delta \sqrt{\rho_{h} f_{y h} f_{m}^{\prime}}$ & $1.292-0.046$ & $0.564-0.000$ & $0.689-0.130$ & $1.222-0.000$ \\
P5 & $\sigma$ & $7.573-0.000$ & $2.685-0.000$ & $8.576-0.000$ & $2.838-0.000$ \\
Output & $v_{n}$ & $5.870-0.000$ & $1.470-0.000$ & $2.760-0.000$ & $1.490-0.000$ \\
\end{tabular}

\subsection{Results obtained}

Table 5 summarises the results of each ANN constructed, varying $\mathrm{n}$, the number of neurons in the hidden layer, from 1 to 3 (usually, the optimal number of $n$ is somewhere between the number of inputs and outputs). For each ANN, the determination coefficient $\left(\mathrm{R}^{2}\right)$ of the correlation, the MSE and the mean and standard deviation of the ratio between the output value provided in the data collected and that given by the neural network $\left(V_{\text {exp }} / V_{n}\right)$ is shown.

As it can be observed, for the CB FG and BR FG typologies, a value of $n$ equal to 1 (i.e. only one neuron is used in the hidden layer) is enough to reach a value of $\mathrm{R}^{2}$ close (or even higher) to 0.90 as well as acceptable values for the mean and the standard deviation of the ratio. On the other hand, $\mathrm{n}$ should be equal to 3 for the BR PG typology in order to reach similar values of $\mathrm{R}^{2}$ and the mean and the standard deviation of the ratio. In the case of the CB PG typology, the values for the determination coefficient are far from 0.90, which indicates that the ANN constructed is not able to suitably connect input and output values. This may be put down to, among other reasons, the lack of values in some part of the range of data. In fact, this typology shows compressive strength values ranging from 4.3 to $18.5 \mathrm{MPa}$. This range is much smaller than those shown by the other studied typologies. Something similar happens with the horizontal reinforcement ratio, where the majority of walls had been tested taking into account a ratio close to $0.2 \%$.

Table 5 - ANN 5-n-1 performance

\begin{tabular}{|c|c|c|c|c|}
\hline \multicolumn{5}{|c|}{ ANN CB FG } \\
\hline $\boldsymbol{n}$ & MSE & $\boldsymbol{R}^{2}$ & Mean $\mathrm{V}_{\text {exp }} / \mathrm{V}_{\mathrm{n}}$ & Std $\mathrm{V}_{\exp } / \mathrm{V}_{\mathrm{n}}$ \\
\hline 1 & 0.066 & 0.885 & 1.000 & 0.177 \\
\hline 2 & 0.044 & 0.922 & 0.994 & 0.171 \\
\hline 3 & 0.039 & 0.931 & 0.997 & 0.151 \\
\hline \multicolumn{5}{|c|}{ ANN BR FG } \\
\hline $\boldsymbol{n}$ & $\boldsymbol{M S E}$ & $\boldsymbol{R}^{2}$ & Mean $\mathrm{V}_{\text {exp }} / \mathrm{V}_{\mathrm{n}}$ & Std $\mathrm{V}_{\text {exp }} / \mathrm{V}_{\mathrm{n}}$ \\
\hline 1 & 0.026 & 0.946 & 1.000 & 0.118 \\
\hline 2 & 0.030 & 0.939 & 1.002 & 0.110 \\
\hline 3 & 0.024 & 0.952 & 0.985 & 0.089 \\
\hline
\end{tabular}

\begin{tabular}{|c|c|c|c|c|}
\hline \multicolumn{5}{|c|}{ ANN CB PG } \\
\hline $\boldsymbol{n}$ & $\boldsymbol{M S E}$ & $\boldsymbol{R}^{\mathbf{2}}$ & Mean $\mathrm{V}_{\exp } / \mathrm{V}_{\mathrm{n}}$ & Std $\mathrm{V}_{\text {exp }} / \mathrm{V}_{\mathrm{n}}$ \\
\hline $\boldsymbol{1}$ & 0.014 & 0.504 & 1.008 & 0.226 \\
\hline $\boldsymbol{2}$ & 0.010 & 0.646 & 1.012 & 0.185 \\
\hline $\mathbf{3}$ & 0.007 & 0.750 & 1.013 & 0.155 \\
\hline \multicolumn{5}{|c|}{ ANN BR PG } \\
\hline $\boldsymbol{n}$ & $\boldsymbol{M S E}$ & $\boldsymbol{R}^{\mathbf{2}}$ & Mean $\mathrm{V}_{\exp } / \mathrm{V}_{\mathrm{n}}$ & $\boldsymbol{S t d} \mathrm{V}_{\text {exp }} / \mathrm{V}_{\mathrm{n}}$ \\
\hline 1 & 0.011 & 0.757 & 1.024 & 0.216 \\
\hline 2 & 0.011 & 0.767 & 1.000 & 0.194 \\
\hline 3 & 0.007 & 0.848 & 1.005 & 0.152 \\
\hline
\end{tabular}




\subsection{Shear expressions based on ANN}

If a single neuron in the intermediate layer is used, the neural network algorithm can be summarised in Equations (11) and (12). It should be noted that the main purpose of the use of a single neuron in this type of studies is to obtain a practical expression that can be applied directly without the need to model an ANN:

$$
\begin{aligned}
& V_{n}=\left[L W\left(\frac{1}{1+e^{-\Omega}}\right)+b_{2}\right] \cdot A_{T} \cdot v_{n, \max } \\
& \Omega=\left(\sum_{i=1}^{5} I W_{i} \cdot p_{i}\right)+b_{1}
\end{aligned}
$$

where $L W$ is the weight of the output (when $\mathrm{n}=1, L W$ is reduced to a $1 \mathrm{x} 1$ matrix) and $b_{2}$ its corresponding bias; $I W$ the input weights matrix (of dimension 1.5) and $b_{l}$ its corresponding biases; $p_{i}$ the input values after being preprocessed according to Equation (10); and $v_{n}$, max the maximum value listed in Table 4 for parameter $v_{n}$ in each ANN constructed.

ANN-based proposals are listed in Table 6. As previously indicated, it unfortunately was not possible to obtain a satisfactory expression for the CB PG typology by means of the ANN constructed for this study. Following the same methodology as used in Section 5.3, the performance of the ANN-based proposals is analysed by means of statistical values. Figure 4 shows the performance of the most accurate shear expressions according to Table 3 together with the ANN-based predictions for each RM typology. As can be observed, the performance of the proposed expressions is better than the other calculation methods studied here, including Tomazevic (1999), Matsumura (1988) and ACI Committee (2005). In general, an improvement of the accuracy is obtained. The mean square error (MSE) is low, the standard deviation decreases, and the 5th percentile is higher than the predictions of existing expressions. This demonstrates that the ANN-based models can be more accurate than existing calculation methods, and so they are recommended as a tool for predicting the shear strength of RM walls. It should be noted that better adjustments are achieved even in complex typologies constructed with partially grouted concrete blocks. Although, in this case, the performance of the neural network model is not good for validating and testing, since, as mentioned above, significantly lower values of $\mathrm{R}^{2}$ are obtained. It should be noted that ANN based proposals are valid only in the parameter range used in this study (listed in Table 4).

Finally, a sensitivity analysis was conducted to study the influence of the different parameters used to build the ANN and thus considered in the equations presented in Table 6. In this study, all parameters except one were kept fixed at their median value (i.e. intermediate point between the maximum and minimum) and the others were varied in the range listed in Table 4. It is important to note that the analysis is performed based on the fitted ANN models and thus it may suffer of some bias interpretation. Figure 5 illustrates the results of this analysis, in which the variation of each parameter is drawn against the variation caused in the value of $V_{n}$ with respect to the value of the shear strength obtained fixing all parameters at their medium value $\left(V_{n_{-} \text {medium }}\right)$. 
The parameter variation scale is established in such a way that $0 \%$ corresponds to the minimum value of the parameter, $50 \%$ to the median value and $100 \%$ to the maximum value of the parameter. As an example, Figure 5(a) shows that if parameter $P 1$ is modified from the median value to the minimum value, keeping the other parameters constant, the shear strength decreases to $18 \%$. On the other hand, if $P 1$ increases to $50 \%$ with respect to its median value, the shear strength increases only a $6 \%$ compared to the medium value of shear strength. Meanwhile, in Figure 5(b), it can be observed that the increase in parameter P2 (horizontal reinforcement) leads to a decrease in $V_{n}$. A similar variation has been noted by Hassanli et al. (2014) in its work on the evaluation of shear strength expressions of four international masonry codes. In general terms, it is observed that P1 is the parameter with more influence in the shear strength predictions for the three typologies. Meanwhile, a less influence is shown by parameters $P 2$ and $P 3$, and to a lesser degree by parameters $P 4$ and $P 5$. As already mentioned, the sensitivity analysis is based on the fitted ANN models and therefore the obtained results are dependent on the form of each parameter considered.

Table 6 - ANN-based proposals

\begin{tabular}{|c|c|}
\hline RM Type & uation* \\
\hline $\begin{array}{l}\text { CB FG } \\
(15)\end{array}$ & $\begin{array}{l}V_{n}=3.12 A_{T}\left(\frac{0.7712}{1+e^{\Omega}}+0.0667\right) \\
\Omega=3.1329 \frac{\left(\frac{M}{V L}\right)^{-1} \sqrt{f_{m}^{\prime}}}{\max P 1}+0.8082 \frac{\rho_{h} f_{y h}}{\max P 2}+2.7827 \frac{\rho_{v} \sqrt{f_{j} f_{y v}}}{\operatorname{maxP3}}+2.0651 \frac{\gamma \delta \sqrt{\rho_{h} f_{y h} f_{m}^{\prime}}}{\operatorname{maxP4}}+2.8501 \frac{\sigma}{\operatorname{maxP5}}-3.527\end{array}$ \\
\hline $\begin{array}{l}\text { BR FG } \\
\text { (16) }\end{array}$ & $\begin{array}{l}V_{n}=2.69 A_{T}\left(\frac{75.9867}{1+e^{\Omega}}-55.0746\right) \\
\Omega \\
\quad=0.0627 \frac{\left(\frac{M}{v L}\right)^{-1} \sqrt{f_{m}^{\prime}}}{\operatorname{maxP1}}+0.0248 \frac{\rho_{h} f_{y h}}{\operatorname{maxP2}}+0.0182 \frac{\rho_{v} \sqrt{f_{j} f_{y v}}}{\operatorname{maxP3}}-0.0385 \frac{\gamma \delta \sqrt{\rho_{h} f_{y h} f_{m}^{\prime}}}{\operatorname{maxP4}}+0.0142 \frac{\sigma}{\operatorname{maxP5}} \\
+0.9545\end{array}$ \\
\hline $\begin{array}{l}\text { BR PG } \\
\text { (17) }\end{array}$ & $\begin{array}{l}V_{n}=1.061 A_{T}\left(\frac{-0.5568}{1+e^{\Omega}}+0.9309\right) \\
\Omega=-8.0997 \frac{\left(\frac{M}{V L}\right)^{-1} \sqrt{f_{m}^{\prime}}}{\max P 1}-6.9163 \frac{\rho_{h} f_{y h}}{\operatorname{maxP2}}-6.1045 \frac{\rho_{v} \sqrt{f_{j} f_{y v}}}{\max P 3}+0.4315 \frac{\gamma \delta \sqrt{\rho_{h} f_{y h} f_{m}^{\prime}}}{\operatorname{maxP4}}-1.1012 \frac{\sigma}{\operatorname{maxP5}}+9.0745\end{array}$ \\
\hline
\end{tabular}

*The terms $\max P 1, \max P 2, \max P 3, \max P 4$ and $\max P 5$ refer to the maximum values for each parameter and RM type listed in Table 4. 

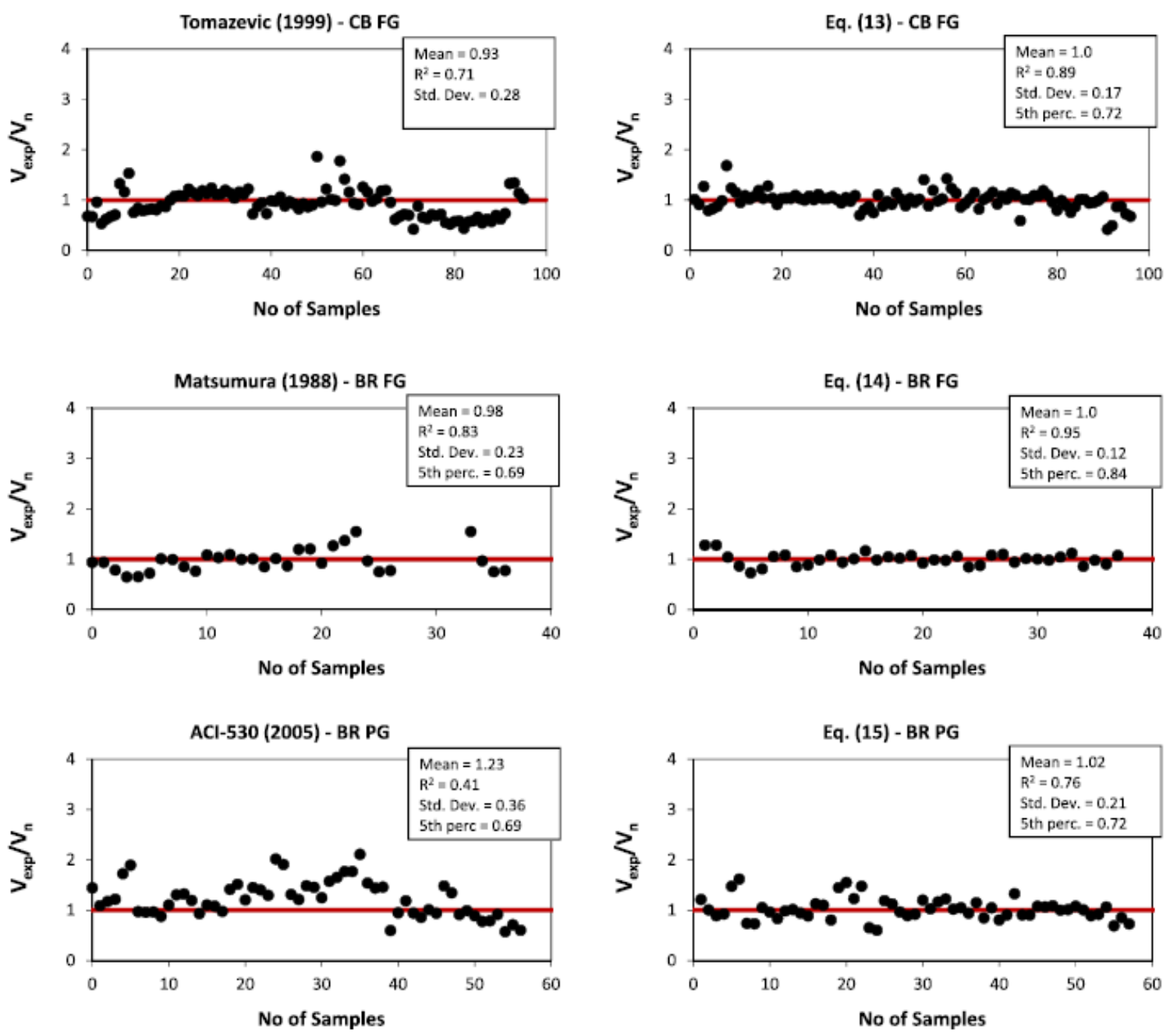

Figure 4-Comparison among the most accurate existing expressions according to Table 3 (left) and the proposed equations (right).
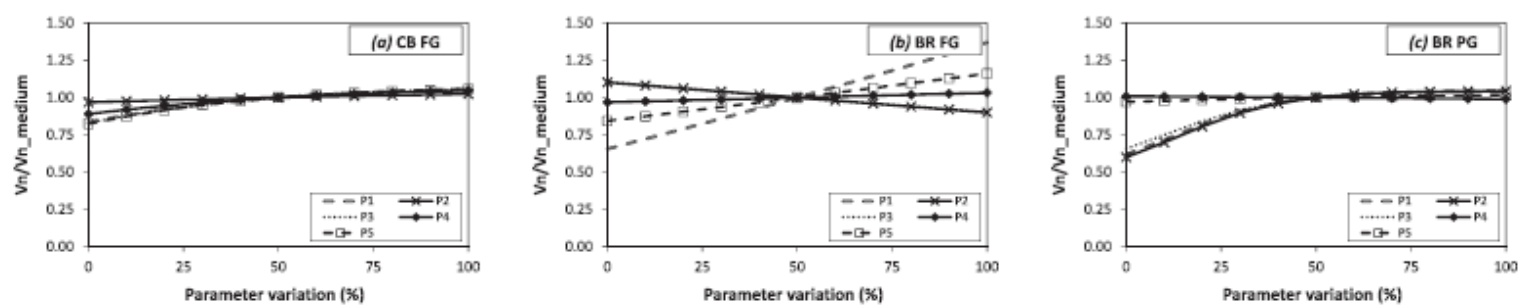

Figure 5 - Sensitivity analysis for equations listed in Table 6: (a) CB FG walls, Equation (13); (b) BR FG walls, Equation (14); (c) BR PG walls, Equation (15).

\section{Conclusions}

The shear strength of RM walls continues to be the subject of extensive investigation. This paper analysed the accuracy and effectiveness of a selection of expressions, including some international masonry codes, 
currently available to estimate the in-plane shear strength of RM walls. As a novel aspect, ANN-based expressions are presented for the assessment of in-plane shear strength of RM walls. These proposals were obtained from a neural network calibrated and validated with 285 experimental results available in the literature.

From the statistical comparison performed with the available expressions, those proposed by Matsumura (1988) and Tomazevic (1999) for fully grouted concrete block masonry and fully grouted ceramic brick masonry, respectively, were the most accurate calculation methods. For masonry in partially grouted conditions, the ACI Committee (2005) code was the most accurate expression. It is important to note that these expressions show a lower 5th percentile, indicating nonconservative predictions. Thus, it is suggested to use the new experimental data generated in recent years to recalibrate these equations. It is noteworthy that the Matsumura (1988) and Tomazevic (1999) proposals do not follow the trend of separating the contributions of the masonry, axial load and reinforcing steel as independent components. On the contrary, these expressions recognize a degree of interdependence between the variables involved in the shear strength mechanisms.

Aiming also at providing an accurate but also practical tool for the evaluation of RM walls, the ANN-based expressions presented here include equations to predict the in-plane shear strength of fully grouted concrete masonry walls (CB FG), fully grouted brick masonry walls (BR FG) and partially grouted brick masonry walls (BR PG). Unfortunately, it was not possible to achieve a satisfactory expression for partially grouted concrete block typology (CB PG) by means of the neurons defined in this study.

The proposed expressions show a good correlation with the experimental database. The parameter P1 $\sqrt{f_{m}^{\prime}} *(M / V L)^{-1}$ proved to be the most influencing parameter on the shear strength predictions. In addition, ANN-based expressions show a comparable accuracy with the equations from Matsumura (1988) and Tomazevic (1999). Compared with the other calculation methods, the ANN-based expressions give less conservative results. These trends were confirmed by comparing the predictions of the different equations with the experimental results obtained by different authors. The proposed methods predicted the experimental results in a more accurate and less conservative way. With sufficient validation, these equations could be applied to practical purposes of design, rehabilitation or retrofit. The predictions could be improved through the inclusion of interdependencies between the variables involved in the mechanisms of the shear response. Moreover, it should be noted that the accuracy of any semi-empirical expression generated would depend on the quality and quantity of the experimental data in the database.

Finally, this research project confirms once again that ANNs can be a reliable approach for resolving complex engineering problems when the only information available consists of the parameters of the problem and the desired results. 


\section{Acknowledgements}

The authors would like to express their sincere gratitude to the anonymous reviewers who made valuable suggestions to improve the technical quality of the paper. This work was supported by the Fondo Nacional de Ciencia y Tecnologia de Chile, (Fondecyt de Iniciacion) [grant number 11121161].

\section{References}

ACI Committee 530. (2005). Building code requirements for masonry structures. Reported by the Masonry Standards Joint Committee.

Boulder, CO: American Concrete Institute Farmington Hills, MI. Aguilar, V. (2013). Estimación de la resistencia al corte de muros de albañilería armada. Estudio comparativo y uso de redes neuronales artificiales [Estimation of shear strength of reinforced masonry walls. Comparative study and use of artificial neural networks]. Memoria de Ingeniero Civil. Valdivia: Universidad Austral de Chile.

Alcaino, P., \& Santa-Maria, H. (2008). Experimental response of externally retrofitted masonry walls subjected to shear loading. Journal of Composites for Construction, 12, 489-498.

Anderson, D., \& Priestley, M. (1992). In-plane shear strength of masonry walls. Proceedings of the 6th Canadian masonry symposium (pp. 223-234). Saskatchewan, Canada: Saskatoon.

Astroza, M., Moroni, M. O., Brzev, S., \& Tunner, J. (2012). Seismic performance of engineered masonry buildings in the 2010 Maule Earthquake. Earthquake Spectra, 28(S1), S385-S406.

Banting, B. R., \& El-Dakhakhni, W. W. (2014). Normal strain-adjusted shear strength expression for fully grouted reinforced masonry structural walls. Journal of Structural Engineering, 140(3), 04013075.

Brunner, J. D., \& Shing, P. B. (1996). Shear strength of reinforced masonry walls. TMS Journal, V14, 6577.

Chen, S., Hidalgo, P., Mayes, R., Clough, R., \& McNiven, H. (1978). Cyclic loading tests of masonry single piers (Report No. UCB/EERC-78/28). Volume 2. Height to width ratio of 1. Berkeley, CA: Earthquake Engineering Research Centre.

CSA Standard S304.1. (2004). Design of masonry structures. Rexdale, ON: Canadian Standards Association.

D’Ayala, D., \& Benzoni, G. (2012). Historic and traditional structures during the 2010 Chile Earthquake: Observations, codes, and conservation strategies. Earthquake Spectra, 28(S1), S425-S451.

Davis, C. L. (2008). Evaluation of design provisions for in-plane shear in masonry walls (Master thesis). Pullman, WA: Washington State University.

da Porto, F., Mosele, F., \& Modena, C. (2011). In-plane cyclic behaviour of a new reinforced masonry system: Experimental results. Engineering Structures, 33, 2584-2596.

Dhanasekar, M., \& Haider, W. (2011). Effect of spacing of reinforcement on the behaviour of partially grouted masonry shear walls. Advances in Structural Engineering, 14, 281-294. 
DICTUC (2014). Ensayo de dos muros de albañilería armada de ladrillo cerámico perforado [Testing of two reinforced masonry walls made of hollow clay bricks]. Informe Técnico: Pontificia Universidad Católica de Chile.

Diez, J. (1987). Estudio experimental de muros de albañilería sometidos a carga lateral alternada [Experimental study of masonry walls subjected to lateral loading]. Memoria de Ingeniero Civil. Santiago: Universidad de Chile.

El-Dakhakhni, W., Banting, B., \& Miller, S. (2013). Seismic performance parameter quantification of shearcritical reinforced concrete masonry squat walls. Journal of Structural Engineering, 139, 957-973.

Elmapruk, J. H. (2010). Shear strength of partially grouted squat masonry shear walls (Master thesis). Pullman, WA: Washington State University.

Fattal, S. G. (1993). Strength of partially-grouted masonry shear walls under lateral loads. Gaithersburg, MD: US Department of Commerce, National Institute of Standards and Technology.

Fattal, S., \& Todd, D. (1991). Ultimate strength of masonry shear walls: Prediction vs. Test results (NISTIR 4633). Gaithersburg, MD: Building and Fire Research Laboratory.

Garzon-Roca, J., Adam, J. M., Sandoval, C., \& Roca, P. (2013). Estimation of the axial behavior of masonry walls based on artificial neural networks. Computers \& Structures, 125, 145-152.

Garzon-Roca, J., Marco, C., \& Adam, J. M. (2013). Compressive strength of masonry made of clay bricks and cement mortar: Estimation based on neural networks and fuzzy logic. Engineering Structures, 48, 21-27.

Ghanem, G. M., Essawy, A. S., \& Hamid, A. A. (1992, June 15-17). Effect of steel distribution on the behavior of partially grouted reinforced masonry shear walls. Proceedings of 6th Canadian masonry symposium, University of Saskatchewan, Saskatoon, Canada.

Ghanem, G.M., Salama, A. E., Elmagd, S. A., \& Hamid, A. A. (1993, June 6-9). Effect of axial compression on the behavior of partially grouted reinforced masonry shear walls. Proceedings of 6th North American masonry conference, Philadelphia, PA.

Haach, V. G., Vasconcelos, G., \& Lourenco, P. B. (2010). Experimental analysis of reinforced concrete block masonry walls subjected to inplane cyclic loading. Journal of Structural Engineering, 136, 452-462.

Haach, V. G., Vasconcelos, G., \& Lourenco, P. B. (2011). Parametrical study of masonry walls subjected to in-plane loading through numerical modeling. Engineering Structures, 33(4), 1377-1389.

Hassanli, R., ElGawady, M. A., \& Mills, J. E. (2014). An evaluation of design code expressions for estimating in-plane shear strength of partially grouted masonry walls. Australian Journal of Structural Engineering, 15, 299-320.

Hidalgo, P., \& Luders, C. (1982). La resistencia prismatica y la Resistencia al esfuerzo de corte de muros de albanileria [Compressive and shear strength of masonry walls]. Primeras Jornadas Chilenas del Hormigon Estructural. Volumen 1. Septiembre 1982. Chile, B-21-B-42. 
Ibrahim, K. S., \& Sutter, G. T. (1999, June 6-9). Ductility of concrete masonry shear walls subjected to cyclic loading. Proceedings of $8^{\text {th }}$ North American masonry conference. Austin, TX.

IMNC. (2010). Normas Tecnicas Complementarias para Diseno y Construccion de Estructuras de Mamposteria [Technical Standards for Design and Construction of masonry structures]. Mexico.

Ingham, J. M., Davidson, B. J., Brammer, D. R., \& Voon, K. C. (2001). Testing and codification of partially grout-filled nominally-reinforced concrete masonry subjected to in-plane cyclic loads. The Masonry Society Journal, 19, 83-96.

Kikuchi, K., Yoshimura, K., Yoshida, K., Tanaka, A., Urasaki, H., Kijima, Y., \& Mizumasa, N. (2004, August 1-6). Experimental study on seismic capacity of reinforced fully grouted concrete masonry walls. Proceedings of 13th world conference on Earthquake engineering. Paper No. 1880. Vancouver, BC, Canada.

Luders, C., \& Hidalgo, P. (1986). Influencia del Refuerzo Horizontal en el Comportamiento sismico de muros de albanileria Armada [Influence of horizontal reinforcement on seismic behavior of reinforced masonry walls]. In IV Jornadas Chilenas de Sismologia e Ingenieria Antisismica. Vina del Mar, Chile.

Luders, C., Hidalgo, P., \& Gavilan, C. (1985). Comportamiento Sismico de Muros de Albanileria Armada. (Proyecto No. 70/83). Santiago: Departamento de Ingenieria Estructural. Pontificia Universidad Catolica de Chile.

Maleki, M. (2008). Behavior of partially grouted reinforced masonry shear walls under cyclic reversed loads (PhD thesis). McMaster University, Canada.

Mansour, M. Y., Dicleli, M., Lee, J. Y., \& Zhang, J. (2004). Predicting the shear strength of reinforced concrete beams using artificial neural networks. Engineering Structures, 26, 781-799.

Marques, R., \& Lourenco, P. B. (2013). A model for pushover analysis of confined masonry structures: Implementation and validation. Bulletin of Earthquake Engineering, 11, 2133-2150.

Matlab 7.0. (2005). User’' s guide. Natick, MA: The Math Works.

Matsumura, A. (1988). Shear strength of reinforced masonry walls. Proceedings of 9th world conference on Earthquake Engineering. Tokyo/ Kyoto, Japan.

Minaie, E., Mota, M., Moon, F. L., \& Hamid, A. A. (2010). In-plane behaviour of partially grouted reinforced concrete masonry shear walls. Journal of Structural Engineering, 136, 1089-1097.

Munoz, W. E. (1992). Estudio experimental del comportamiento de muros de albanileria de bloques de hormigon sometidos a carga lateral alternada [Experimental study on in-plane cyclic behavior of reinforced concrete masonry walls]. Memoria de Ingeniero Civil. Santiago: Universidad de Chile.

Nolph, S. M., \& ElGawady, M. A. (2012). Static cyclic response of partially grouted masonry shear walls. Journal of Structural Engineering, 138, 864-879. 
NZS 4230. (2004). Design of reinforced concrete masonry structures. Wellington: Standards Association of New Zealand.

Okamoto, S., Yamazaki, Y., Kaminosono, T., Teshigawara, M., \& Hirashi, H. (1987). Seismic capacity of reinforced masonry walls and beams. Proceedings of 18th joint meeting of the U.S. Japan cooperative programs in natural resource panel on wind and seismic effects (pp. 307-319).

Gaithersburg, MD. Plevris, V., \& Asteris, P. G. (2014). Modeling of masonry failure surface under biaxial compressive stress using neural networks. Construction and Building Materials, 55, 447-461.

Psilla, N., \& Tassios, T. P. (2009). Design models of reinforced masonry walls under monotonic and cyclic loading. Engineering Structures, 31, 935-945.

Ramirez, P., Sandoval, C., \& Almazan, J. L. (2015). Experimental assessment of shear strength and displacement capacity of partially grouted reinforced concrete masonry shear walls. In 11th Canadian conference on Earthquake engineering. Victoria BC, Canada.

Sandoval, C., \& Roca, P. (2012). Study of the influence of different parameters on the buckling behaviour of masonry walls. Construction and Building Materials, 35, 888-899.

Sandoval, C., Roca, P., Adam, J. M., \& Garzon-Roca, J. (2014). Modelling of buckling failure of load bearing walls. Proceedings of 9th international masonry conference, Guimaraes, Portugal.

Sandoval, C., Calderon, S., Almazan, J. L., \& Tapia, N. (in press). In-plane cyclic shear tests of partially grouted masonry walls with ladder-type bed-joint reinforcement.

Schultz, A. E. (1994). NIST research program on the seismic resistance of partially-grouted masonry shear walls. Gaithersburg, MD: US Department of Commerce, National Institute of Standards andTechnology.

Schultz, A. E., Hutchinson, R. S., and Cheok, G. C. (1998). Seismic performance of masonry walls with bed joint reinforcement. Proceedings of Structural Engineers World Congress, July 18-23, Paper T119-4. San Francisco, CA.

Sepulveda, M. (2003). Influencia del Refuerzo Horizontal en el Comportamiento Sismico de Muros de Albanileria [Influence of horizontal reinforcement on seismic behavior of reinforced masonry walls]. Memoria de Ingeniero Civil. Santiago: Pontificia Universidad Catolica de Chile.

Shedid, M. T., Drysdale, R. G., \& El-Dakhakhni, W. (2008). Behavior of fully grouted reinforced concrete masonry shear walls failing in flexure: Experimental results. Journal of Structural Engineering, 134, 17541767.

Sherman, J. D. (2011). Effects of key parameters on the performance of concrete masonry shear walls under in-plane loading (PhD thesis). Pullman, WA: Washington State University.

Shing, P. B., Noland, J. L., Klamerus, E., \& Spaeh, H. (1989). Inelastic behavior of concrete masonry shear walls. Journal of Structural Engineering, 115, 2204-2225. 
Shing, P., Schuller, M., \& Hoskere, V. (1990). In - plane resistance of reinforced masonry shear walls. Journal of Structural Engineering, 116, 619-640.

Sierra, G. A. (2002). Estudio experimental de la influencia del refuerzo vertical en muros de albanileria armada sometidos a carga lateral alternada [Influence of vertical reinforcement on reinforced masonry walls under cyclic lateral loading. An experimental study]. Memoria de Ingeniero Civil. Santiago: Universidad de Chile.

Šipoš, T. K., Sigmund, V., \& Hadzima-Nyarko, M. (2013). Earthquake performance of infilled frames using neural networks and experimental database. Engineering Structures, 51, 113-127.

Sucuoglu, H., \& McNiven, H.D. (1991). Seismic shear capacity of reinforced masonry piers. Journal of Structural Engineering, 117, 2166-2185.

Sveinsson, B. I., Mayes, R. L., \& McNiven, H. D. (1985) Cyclic loading of masonry single piers (Rep. No. UCB/EERC-85/15). Volume 4. Additional test with height to width ratio of 1. Berkeley, CA: Earthquake Engineering Research Centre.

Tomazevic, M. (1999). Earthquake-resistant design of masonry buildings. London: Imperial College Press.

Tomaževič, M., Lutman, M., \& Petković, L. (1996). Seismic behaviour of masonry walls: Experimental simulation. Journal of Structural Engineering, 122, 1040-1047.

UBC. (1997) Uniform Building Code. International conference of building officials. Whittier, CA.

Valdebenito, G., Alvarado, D., Sandoval, C., \& Aguilar, V. (2015, March 18-20). Terremoto de Iquique Mw 8.2 - 01 de abril de 2014: danos observados y efectos de sitio en estructuras de albanileria [Iquique earthquake (Mw8.2) - April 1, 2014: observed damage and site effects in masonry structures]. In XI Congreso Chileno de Sismologia e Ingenieria Sismica, Santiago, Chile.

Voon, K. C. (2007). In-plane seismic design of concrete masonry structures (PhD thesis). Auckland: University of Auckland.

Voon, K. C., \& Ingham, J. M. (2006). Experimental in-plane shear strength investigation of reinforced concrete masonry walls. Journal of Structural Engineering, 132, 400-408.

Voon, K. C., \& Ingham, J. M. (2007). Design expression for the in-plane shear strength of reinforced concrete masonry. Journal of Structural Engineering, 133, 706-713.

Yancey, C., \& Scribner, C. F. (1989). Influence of horizontal reinforcementon shear resistance of concrete block masonry walls. NISTER, 89, 4202. 